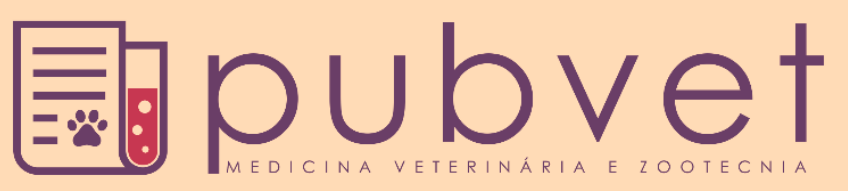

https://doi.org/10.31533/pubvet.v16n02a1043.1-9

\title{
Diagnóstico gestacional em ratas de laboratório: Revisão
}

\author{
Rafaela Prado Gomes $^{1 * \bullet}$, Janiscleidy dos Santos Silva ${ }^{2} \bullet$, Mariana Paes dos Anjos ${ }^{30}$ \\ ${ }^{I}$ Médica veterinária; Aracaju, Sergipe, Brasil. \\ ${ }^{2}$ Graduanda do curso de Medicina Veterinária da Associação de Ensino e Cultura Faculdade Pio Décimo; Aracaju, Sergipe, Brasil. \\ ${ }^{3}$ Bacharel em medicina veterinária; Aracaju, Sergipe, Brasil. \\ *Autor para correspondência, E-mail: rafaelap_19@hotmail.com
}

\begin{abstract}
Resumo. Há décadas que os ratos são utilizados como modelos de experimentos dentro de laboratórios devido ao fato de mostrarem uma melhor representação do funcionamento dos sistemas humanos quando comparado a outros mamíferos, uma vez que possuem respostas fisiológicas semelhantes. O seu ciclo de vida e reprodutivo são curtos, o que os torna objetos centrais de estudos comportamentais, toxicológicos, reprodutivos e biomédicos. Por conta disso, um diagnóstico mais assertivo rápido faz-se necessário, bem como a confirmação dos números, a idade e o desenvolvimento embriológico, o que não poderia ser alcançado através da metodologia convencional adotada atualmente. Apesar da ultrassonografia ser considerada uma técnica não invasiva e amplamente utilizada na clínica médica, seu uso em animais de experimentação ainda é escasso, assim como as pesquisas publicadas a respeito do assunto.
\end{abstract}

Palavras-chave: Rato, diagnóstico, ultrassom

\section{Gestacional diagnose in laboratory rats: Review}

\begin{abstract}
Rats have been used for decades as model of experimente in the laboratory due to the fact it shows the best representation of the functions of human sistems when compared of the others mammals, since it has similar physiological response. It cycle of live and reproductive are short, which make it the central object of behavioral, toxicological, reproductive and biomedical studies. Because of that, a diagnosis more correct and quickly it is necessary, as well as the confirmation of numbers, age and the embryological development, which couldn't be achieved through the convencional methodology adopted nowadays. Although the ultrasound is considered a noninvasive technique and widely used in the medical clinic, its uses in experimentation animals it is still scarce, as well as the published researches about the subject.
\end{abstract}

Keywords: Rats, diagnosis, ultrasound

\section{Introdução}

O Rattus norvegicus, também reconhecido como rato de laboratório, é o animal mais utilizado como modelo para experimentos farmacológicos, fisiológicos, toxicológicos, comportamentais e dentre outros. Isso ocorre devido ao seu sistema se assemelhar ao dos seres humanos, além do seu período gestacional ser curto, assim como o seu tempo de vida. Eles são mais utilizados na biomedicina e em pesquisa comportamental, podendo ser usado como pesquisa de doenças cardiovasculares, transplante de órgãos, desordem neurológica e metabólica, susceptibilidade ao câncer, doenças renais, neurológicas e autoimunes e estudos neurológicos. Os resultados obtidos através das pesquisas realizadas nessa espécie podem ser convertidos para o desenvolvimento de novos agentes terapêuticos e estudos a respostas acerca de agentes ambientais. 
Convencionalmente, a gestação pode ser estabelecida após observar a ocorrência da cópula, aumento do volume do abdômen inferior à palpação, a queda dos pelos ao redor dos mamilos e o seu crescimento e o monitoramento do ganho de peso. Dentro do campo da ciência há o interesse que, após ter ocorrido a reprodução, que o diagnóstico de gestação aconteça o mais rápido e preciso possível, bem como um maior detalhamento das características do feto. No entanto, os métodos de diagnóstico utilizados atualmente para a deteç̧ão de gravidez não preenchem as exigências impostas, especialmente quando as tentativas de determinar os períodos de início e meio da gestação. A utilização do ultrassom para a avaliação do útero em ratas é um método confiável não invasivo, no qual não representa nenhum risco para o feto. Esse exame, apesar de ser bastante utilizado na clínica médica de pequenos e grandes animais, não é observado em ratas para a confirmação de prenhez e poucos são os estudos que seus casos são relatados.

O presente trabalho possui como objetivo fazer uma síntese acerca dos estudos realizados sobre a utilização da ultrassonografia como uma ferramenta para o auxílio no diagnóstico de gestação em ratas, descrevendo as técnicas encontradas e suas conclusões.

\section{Rattus Norvegicus}

Os ratos possuem uma curta duração de vida, por volta de dois a três anos, vivendo em grupos e estabelecem relações sociais. Conhecido por diversos nomes, como rato de laboratório ou Norway, por exemplo, os Rattus norvegicus são animais considerados por muitos como pestes. Há relatos históricos datando acerca da presença dos ratos Norway dentro do continente europeu do século 18. Eles foram bastante utilizados durante o século 19 como uma forma de entretenimento e esportes na Europa e posteriormente na América, a isca de rato, na qual as pessoas apostavam em qual cachorro terrier poderia matar o maior número de ratos confinados em uma cova num período de tempo. Dentro desse mesmo século e no anterior, os ratos eram presos, mortos, vendidos por comida, especialmente quando a Europa passava por uma crise de fome (Krinke, 2000).

Contudo, foi no início do século 19 em que os ratos albinos (Wistar) foram introduzidos nos laboratórios para servirem como objetos de estudo. Apesar de existir cientistas que apontam ter utilizados esporadicamente ratos em experimentos antes de 1850, o primeiro estudo documentado foi publicado em 1856 na França conduzido nesses animais foi o trabalho sobre os efeitos da adrenalectomia; e quem iniciou a utilização deles em estudos psicológicos foi Adolph Mayer, que na época era um psicólogo bastante reconhecido. Depois de 1893, o neurologista Henry Herbert Donaldson, após assumir o cargo de diretoria no Instituto Wistar, pretendia padronizar o rato albino para criar um modelo universal adequado para as pesquisas biomédicas (Modlinska \& Pisula, 2020).

Os primeiros experimentos de melhoramento genético que há documentado são os realizados por Crampe, começando em 1877 chegando até 1885, que se sucedeu pouco depois pelas pesquisas de Mendel, muito antes de em 1900 a redescoberta das leis de Mendel relatar as leis da herança da cor da pelagem, relatando o albinismo, o preto recessivo e os resultados obtidos pelas proles em diferentes cruzamentos experimentais (Krinke, 2000).

Psicólogos, fisiológicos e comparativos realizavam estudos comportamentais conduzidos em animais. $\mathrm{O}$ intuito das pesquisas era a descoberta das leis gerais, nas quais acreditava-se que podiam ser aplicadas em qualquer espécie em qualquer circunstância, explicando que a conveniência determinava as escolhas, mais do que a teoria ou considerações ecológicas, da espécie estudada. Durante os anos de 1930 e 1940, mais que 60\% de todos os artigos publicados em dois dos principais jornais de comportamento animal da época (o Journal of Comparative and Physiological Psychology e o Journal of Animal Behavior) estavam preocupados com o comportamento de um único organismo, o rato Norway (Galef, 2010).

Desde então essa espécie tem sido amplamente estudada e usada em importantes linhas de pesquisas comportamentais, da biomedicina, na neurologia, nutricional, na endocrinologia e na grande variedade de conhecimento que foi adquirido, especialmente na matéria de fisiologia e a compreensão que se formou acerca da genética. Outra característica que reforça a importância do rato para atuar no laboratório é a sua gestação ter uma duração mais curta, assim como o seu tempo de vida. Os ratos também são um modelo padrão para a realização de testes toxicológicos, teratológico e carcinogênico 
(Otto et al., 2015). Do mesmo modo que as áreas como a medicina experimental, tendo o transplante em foco, afecções autoimunes e outras disfunções imunológicas, estudos sobre o câncer, a hipertensão, a diabetes e a artrite. Isso ocorre devido a eles serem considerados os melhores modelos do funcionamento do sistema dos mamíferos (Krinke, 2000).

\section{Reprodução}

Em comparação a outros animais maiores, os ratos possuem um ciclo reprodutivo menor, começando pela puberdade, o ciclo estral, a gravidez e a lactação. Por esse motivo eles são bastante utilizados para estudos da fisiologia da reprodução (Otto et al., 2015). De acordo com Raineki (2006), eles são capazes de procriar com oito semanas de vida; porém, recomenda-se que o acasalamento ocorra por volta da $12^{\mathrm{a}}$ semana de idade. Possuem um ciclo estral de cinco dias e a gestação de 21 a 23 dias, com uma ninhada em média de seis a 12 filhotes.

O comportamento sexual das fêmeas foi classificado de acordo com três principais critérios: atratividade, proceptividade e receptividade. Sendo que nessa categorização, tanto na teoria quanto na prática, a proceptividade e a receptividade são semelhantes. Os hormônios esteroidais sexuais, principalmente o estrógeno, é responsável pelo comportamento sexual dos ratos, uma fêmea proceptiva começa a cópula mostrando uma postura de lordótica, o que também demonstra sua receptividade (Krinke, 2000).

Esse comportamento é típico para indicar receptividade, sendo caracterizado pela dorsoflexão da coluna vertebral, que é bastante utilizado para averiguar os mecanismos fisiológicos que regulam o comportamento sexual feminino e sua diferenciação sexual, com os esteroides ovarianos, como o estrógeno e a progesterona, sendo necessários para a sua manifestação. O estrogênio sozinho é suficiente para induzir a lordose, enquanto a progesterona complementa a expressão do comportamento sexual. Em machos, o olfato tem uma importante função para induzir ao comportamento sexual (Krinke, 2000).

De acordo com Magalhães (2012), o cio das ratas ocorre durante o período crepuscular, no qual 64\% deles acontecem entre o intervalo de 18 horas às 6 horas. $O$ proestro com duração aproximada de 24 a 36 horas, característico com a tumefação e congestão dos genitais externos e um ligeiro descarregamento seroso na vagina.

Segundo Krinke (2000), as variações sazonais não foram relatadas em ratas de laboratório. A ovulação das fêmeas geralmente acontece entre oito a 11 horas após o estro ter dado início, decorrendo por volta da meia noite e às duas da manhã, devido ao fotoperíodo exercer grande influência no eixo hipotálamo-hipófise-gonadal do animal, com o tempo em que a proporção do hormônio liberador de gonadotrofina $(\mathrm{GnRH})$ para o hormônio luteinizante $(\mathrm{LH})$ está mais elevado também ligado ao sistema circadiano.

Conforme Davis (1951), os machos possuem esperma e órgãos sexuais secundários maduros durante todas as estações do ano, não possuindo nenhuma evidência de uma regressão testicular durante as temporadas, o que é usualmente visto nos roedores da família Cricetidae.

Além da iluminação, existem outros fatores que influenciam na reprodução, tais como a nutrição, o estresse e a lactação. O coeficiente nutricional é essencial para a regulação da atividade gonadal. Ao ser submetida a jejum durante o início do estro, há uma supressão da secreção pulsátil do LH assim como o próximo pico de LH no proestro, o que pode levar a distúrbios da ovulação. A eliminação da onda de LH é mediada por hormônios mediados por corticotropina e outros tipos de estresse. Por outro lado, o estresse inibe fortemente a atividade do eixo hipotálamo-pituitáriagônada do rato, havendo estudos afirmando que, ao serem submetidos a situações estressantes, na ausência ou não de estrogênio, o pulso de LH é imediatamente suprimido. E a estimulação da sucção pode inibir significativamente a secreção de LH (Krinke, 2000).

Os hormônios sexuais esteroidais, especialmente o estrogênio, são responsáveis por todos estes componentes do comportamento sexual: a atratividade, a suscetibilidade e a receptividade. Uma rata receptiva inicia o acasalamento e mostra uma postura lordótica e também mostra sua receptividade. Esse comportamento é caracterizado por uma dorsiflexão da coluna vertebral (Krinke, 2000). 


\section{Gestação e parto}

No início da gestação, não é fácil de detectar quando a rata está gestante. Aproximadamente depois de 10 dias após a cópula, é possível perceber o crescimento dos fetos por meio de uma minuciosa palpação, porém após 12 dias esse trabalho se torna mais preciso (Galef, 2010).

Segundo Ypsilantis et al. (2009), os sinais que indicam a gestação das ratas na prática são o crescimento abdominal (que ocorre no dia 13), desenvolvimento mamário e aumento dos mamilos (no dia 14) e o aumento do seu peso corporal, assim como o consumo de alimentos. A confirmação acontece quando ocorre o parto. Nas fêmeas gestantes, a produção de progesterona é realizada especialmente pelo ovário e posteriormente, na segunda metade da gestação, ela é unicamente pela placenta. Durante a gravidez, os ovários continuam a produzir estrogênio, o que leva à ativação do corpo lúteo. Esse hormônio é essencial para a manutenção do corpo lúteo, estimulando a vascularização e a produção de hormônios esteroidais (Krinke, 2000).

Carmo et al. (2007) reúnem trabalhos acerca da cronologia do desenvolvimento embrionário e fetal de ratos (Tabela 1), na qual o critério para a datação do primeiro dia da prenhez considerado pela maioria dos autores relatado no estudo foi a presença de espermatozoides no esfregaço vaginal. Alguns dos dados apresentados possuem discordância entre os autores, por isso foi escolhido expor o que a maioria coincidia. Além disso, nem todas as informações são perceptíveis utilizando a ultrassonografia.

Tabela 1. Desenvolvimento embrionário dos ratos (Carmo et al., 2007)

(continua)

\begin{tabular}{|c|c|}
\hline Desenvolvimento embrionário dos ratos & Dias após o coito \\
\hline$\overline{\text { Zigoto. }}$ & 1 \\
\hline Duas células no oviduto. & 2 \\
\hline Quatro células no oviduto. & 3 \\
\hline Oito a doze células no oviduto. & 4 \\
\hline Mórula no útero. & 3,25 \\
\hline Blastocisto expandido e eclodido no útero. & 5 \\
\hline Implantação do blastocisto. Endoderma começa a diferenciar-se. & 6 \\
\hline Desenvolvimento do saco vitelino. & 6 \\
\hline Formação do epiblasto. & 7,25 \\
\hline $\begin{array}{l}\text { Surge o cone ectoplacentário e o cilindro embrionário diferencia-se em duas regiões: embrionária } \\
\text { e extraembrionária. }\end{array}$ & $7,27-7,75$ \\
\hline Aparecimento da linha primitiva e início da diferenciação do terceiro folheto embrionário. & 8,5 \\
\hline Nó primitivo torna-se visível. & 8,5 \\
\hline Formação do exoceloma e surgimento do broto alantóico. & $8,5-9$ \\
\hline Surge o primórdio do coração. & 8,5 \\
\hline Placa notocordal visível. & $8,5-9$ \\
\hline Desenvolvimento da placa neural e processo cefálico. & $8,5-9$ \\
\hline Intestino primitivo começa a se formar. & $8-9$ \\
\hline Delimitação do sulco ótico & $9-10$ \\
\hline Aparecimento dos somitos. & $9-10$ \\
\hline Início do fechamento do sulco neural. & $9-10$ \\
\hline A notocorda está completamente formada. & 10,5 \\
\hline Sulco óptico torna-se progressivamente aprofundado. & 10,5 \\
\hline Aparecimento do arco branquial. & $9-12,75$ \\
\hline \multicolumn{2}{|l|}{ Componentes maxilares do arco branquial tornam-se proeminentes. } \\
\hline Fechamento do neuroporo anterior. & 10 \\
\hline $2^{\circ}$ arco branquial torna-se evidente. & 10 \\
\hline $3^{\circ}$ arco branquial. & $10-11$ \\
\hline Aparecimento do broto respiratório no assoalho do intestino primitivo faríngeo. & $11-11,5$ \\
\hline Separação entre traquéia e esôfago. & 12 \\
\hline Processo maxilar se une ao processo nasal lateral. & $11-12$ \\
\hline Coração com ventrículo comum. & 11 \\
\hline Linha primitiva desaparece. & 11 \\
\hline Projeção da bolsa de Rathke's. & $11-13$ \\
\hline Fechamento do neuroporo posterior. & $11-12$ \\
\hline Cérebro primitivo dividido em telencéfalo e diencéfalo. & $11-11,75$ \\
\hline Esboço dos brotos dos membros anteriores. & 11 \\
\hline Esboço dos brotos dos membros posteriores. & $11-13$ \\
\hline Massa hepática dividida em 4 lóbulos. & 12 \\
\hline Vascularização e inervação dos brotos dos membros anteriores. & 12,75 \\
\hline
\end{tabular}


Tabela 1. Desenvolvimento embrionário dos ratos (Carmo et al., 2007)

(continuação)

\begin{tabular}{lc}
\hline Desenvolvimento embrionário dos ratos & Dias após o coito \\
\hline Cavidade ótica estreita-se e forma-se a saliência auditiva & $12,75-13$ \\
Cavidade nasal começa a se formar. & $12-12,75$ \\
A vesícula da lente está fechada. & $12-13$ \\
Formação do broto da caudal. & $11-12$ \\
Processos nasais começam a se formar. & $11,87-12,75$ \\
Brotos dos membros anteriores divididos em regiões proximal (futuros braço e antebraço) e distal & $12,75-13$ \\
(patas primitivas). & $11,75-12$ \\
Presença de quatro pares de arcos branquiais. & 13 \\
A língua torna-se visível. & 13,5 \\
Fissura do 10 arco branquial transforma-se em ducto do ouvido externo. & $12,75-13$ \\
Desenvolvimento da crista mamária. & 12,25 \\
Formação da hérnia umbilical. & $13-15$ \\
Hérnia umbilical conspícua. & 14 \\
Protuberâncias auriculares nos arcos branquiais 1 e 2. & $14-14,5$ \\
Orelha desenvolve-se rapidamente. & 14 \\
Notocorda apresenta estrutura linear próxima a esclerótomos. & $14-14,5$ \\
Folículos pilosos proeminentes sobre os olhos e orelhas. & $13,5-15$ \\
As cartilagens das patas são visíveis. & 15 \\
Início da ossificação. & 15 \\
Folículos pilosos presentes nas regiões peitoral, pélvica e tronco. & 15,5 \\
Hérnia umbilical atinge seu tamanho máximo. & $13-14$ \\
Arcos radiais aparecem nas patas primitivas anteriores e posteriores. & $15-17$ \\
Dedos individualizados nas patas anteriores. & 15,5 \\
Folículos pilosos na região cefálica. &
\end{tabular}

A pseudociese tem a duração entre 12 a 14 dias, sendo mais curta ao ser comparada com a gestação. Nela, a função lútea é mantida por um aumento da secreção de prolactina após uma estimulação cervical, o que induz a dois surtos diários de prolactina, chamados de surtos diurnos e noturnos, ocorrendo por volta das 17:00 até às 19:00 e 03:00 até às 7:00, respectivamente. Essa pseudogestação pode ser um bom modelo para a análise do mecanismo que regula a longevidade do corpo lúteo ou luteólise, uma vez que a duração do corpo lúteo durante a pseudociese das ratas é bastante semelhante a outras espécies de mamíferos (Krinke, 2000).

De acordo com Galef (2010), aproximadamente cinco dias antes do parto, as fêmeas aumentam a sua atividade de construir um ninho e continua durante a lactação. Geralmente uma hora e meia a quatro horas antes do nascimento dos filhotes, há um corrimento vaginal de um líquido claro mucoso.

O parto pode acontecer no dia 21 ou 22 da gestação, durante o período da manhã. Sob as condições de 14 horas de luz e 10 horas de escuro (14L:10E), na qual as luzes são acesas às 5:00, é relatado que $37 \%$ das ratas dão à luz durante a manhã no dia $21,20 \%$ durante a noite do dia 21 ou 22 e $42 \%$ durante o período matutino do dia 22. Os picos de parto ocorrem são das 13:00 às 15:00 do dia $21 \mathrm{e}$ o outro às 9:00 até às 11:00 no dia 22 (Krinke, 2000).

\section{Ultrassonografia}

Os ratos são vastamente utilizados para pesquisas reprodutivas, estudos acerca da fertilidade, desenvolvimento durante a gestação e a toxicologia reprodutiva, o que torna ideal um diagnóstico com antecedência e preciso, bem como a descrição detalhada dos fetos, a confirmação dos números, a idade e o desenvolvimento embriológico. Contudo, as formas de diagnóstico usadas atualmente não preenchem essas necessidades, principalmente para determinar o início e meio da gestação. Apesar da ultrassonografia ser profusamente empregado tanto na rotina médica humana e veterinária, não é comumente aplicado em estudos com animais de laboratório. A utilização dessa técnica no útero é um método não invasivo, representa nenhum risco aos fetos quando usado no nível de intensidade recomendado (Stasinopoulou et al., 2014; Ypsilantis et al., 2009).

No estudo realizado por Inaba et al. (1986), foram utilizados no total de 100 ratos Wistar, mantidos em um ambiente refrigerado com ar-condicionado e iluminação controlada (14L:10E). Quando a fêmea aparentava estar no estro, os ratos copulavam naturalmente. Depois do encontro, as fêmeas foram anestesiadas com éter e diariamente testadas para o diagnóstico de gravidez com um aparelho de 
ultrassom, o hitachi EUB-25M, com $61 \mathrm{~mm}$, transdutor de matriz linear de cinco $\mathrm{MHz}$ (profundidade de foco quatro $\mathrm{cm}$ ); a confirmação ou a ausência de gestação só era confirmada com os registros dos nascimentos, o conteúdo alimentar e os gases não impediram a visualização durante o exame.

Antes do dia 7 de gestação, não foi possível a visualização do útero, sendo considerado o dia 0 aquele em que ocorreu a cópula. Já no dia 8 , a imagem do útero foi reconhecida em quatro ratas gestantes, porém onze das que eram tidas como "não grávidas", posteriormente foi confirmado que oito delas estavam prenhas. No dia 9, houve um crescimento na porcentagem de acerto no diagnóstico, chegando aos $83 \%$ (Tabela 2); chegando aos $100 \%$ no dia 10. Após o dia 14 de gestação, foi possível detectar os fetos no útero gravídico; depois do dia 19, detalhes fetais como a espinha do feto e os batimentos cardíacos foram perceptíveis; elas deram à luz no dia 22.

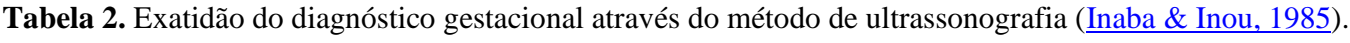

\begin{tabular}{|c|c|c|c|c|c|c|}
\hline \multirow{3}{*}{$\begin{array}{l}\text { Dias depois da } \\
\text { cópula }\end{array}$} & \multirow{3}{*}{$\begin{array}{l}\mathrm{N}^{\circ} \text { de ratas } \\
\text { examinadas }\end{array}$} & \multicolumn{4}{|c|}{ Diagnóstico } & \multirow{3}{*}{$\begin{array}{l}\text { Porcentagem } \\
\text { final de } \\
\text { diagnóstico } \\
\text { correto }(\%)\end{array}$} \\
\hline & & \multicolumn{2}{|c|}{ "Grávida" } & \multicolumn{2}{|c|}{ "Não grávida" } & \\
\hline & & $\mathrm{N}^{\circ}$ de ratas & $\begin{array}{c}\mathrm{N}^{\circ} \text { de diagnóstico } \\
\text { correto }\end{array}$ & $\mathrm{N}^{\mathrm{o}}$ de ratas & $\begin{array}{c}\mathrm{N}^{\circ} \text { de diagnóstico } \\
\text { correto }\end{array}$ & \\
\hline$<7$ & 26 & 0 & 0 & 26 & 3 & 12 \\
\hline 8 & 15 & 4 & 4 & 11 & 3 & 47 \\
\hline 9 & 12 & 8 & 8 & 4 & 2 & 83 \\
\hline 10 & 12 & 9 & 9 & 3 & 3 & 100 \\
\hline$>11$ & 35 & 32 & 32 & 3 & 3 & 100 \\
\hline
\end{tabular}

Já na pesquisa realizada por Ypsilantis et al. (2009) foram utilizadas quarenta ratas Wistar multíparas, com a idade entre 6 a 8 meses de idade, o peso variando entre 300 a $350 \mathrm{~g}$; foi usado uma máquina ultrassonográfica disponível comercialmente (HDI 1500), que era comumente aplicada na medicina humana, equipada com transdutor linear de cinco a $12 \mathrm{MHz}$, utilizando a frequência de $12 \mathrm{MHz}$. Os animais eram mantidos em gaiolas de policarbonato, com 3 ratos por gaiola, em um ambiente refrigerado entre 20 a $22^{\circ} \mathrm{C}$, com ciclo claro:escuro de 14L:10E, sendo ofertada uma alimentação granulada comercial e água à disposição.

A proporção de macho e fêmea para o acasalamento era de 1:1. Para o diagnóstico as fêmeas foram submetidas à anestesia geral ( $2 \%$ de sevoflurano em oxigênio) e um exame transabdominal ultrassonográfico de seus úteros antes da cópula e do dia 8 ao 16 (o dia 0 ficou definido o dia da cópula, na qual foi confirmada pela constatação de espermatozoides ao ser realizado esfregaço vaginal), com metade das fêmeas sendo observadas nos dia 8,10,12,14 e 16, enquanto as demais eram analisadas nos dias $9,11,13$ e 15 , com o intuito de diminuir possíveis efeitos causados pela anestesia e contínua exposição ao ultrassom.

Todas as fêmeas deram a luz no dia 21 e 22 . As evidências de gravidez que eram observadas e descritas foram: a dimensão, forma e ecogenicidade da vesícula embrionária; a presença e frequência do batimento cardíaco embrionário; comprimento embrionário crown-rump (CCR), que se trata do comprimento do corpo do feto. Os diâmetros transversais e longitudinais das vesículas embrionárias foram mensurados ao aparecer na tela a maior área de superfície, o Doppler colorido foi usado para detectar os batimentos cardíacos do embrião.

Útero normal não foi visualizado em fêmeas não grávidas e nem no dia 8 . No dia 9 , a porcentagem de falso negativo diagnosticado foi de $25 \%, 5$ dos 20 animais examinados; já no dia 10, esse percentual diminuiu para 8\%, 2 dos 25 animais estudados; depois disso, o percentual caiu para $0 \%$. Nos dias 9 a 11 foi possível detectar vesículas embrionárias cheias de líquido, reconhecíveis como estruturas redondas ou ovais de ecogenicidade intermediária no lúmen do corno uterino.

As bordas ventral e dorsal das paredes uterinas estavam representadas nas seções longitudinais por duas finas linhas hiperecóicas paralelas adjacentes à vesícula embrionária. As dimensões (longitudinal, transversal e o diâmetro médio) dessa vesícula desde o dia 9 ao 11 estão configuradas na tabela 3 . Já no dia 12, foi possível reconhecer os embriões dentro da vesícula embrionária de forma oval, com batimento cardíaco mensurável e CCR (Tabela 3). Ambos os parâmetros apresentaram aumento como o avançar da idade gestacional. No dia 13 a placenta foi identificada como uma estrutura hiperecóica de forma elipsoidal. 
Durante os dias 11 ao 16, foram mensuráveis as medidas aproximadas de CCR e comparada sua evolução (Tabela 4), porém essas medidas obtidas pelo ultrassom foram menores do que os dados embriológicos relatados. Essa diferença que ocorreu pode ser atribuída à curvatura do embrião durante esses dias. Outra explicação possível é a variação do tamanho do filhote dependendo do número de fetos gestados. No dia 12, houve a confirmação da gestação através da detecção dos batimentos cardíacos embrionários.

Tabela 3. Dimensão das vesículas embrionárias, comprimento de crown-rump e frequência cardíaca em batimentos por minuto (bpm) (em média \pm 1 de desvio padrão) de conceptos avaliados ultrassonográficos em ratas grávidas (Ypsilantis et al., 2009)

\begin{tabular}{|c|c|c|c|c|c|c|c|}
\hline \multirow{2}{*}{$\begin{array}{l}\text { Dias de } \\
\text { gestação }\end{array}$} & \multicolumn{3}{|c|}{ Diâmetro da vesícula embrionária $(\mathrm{cm})$} & \multirow{2}{*}{$\begin{array}{c}\text { Comprimento } \\
\text { crown-rump }(\mathrm{cm})\end{array}$} & \multirow{2}{*}{$\begin{array}{c}\text { Frequência } \\
\text { cardíaca }(\mathrm{bpm})\end{array}$} & \multirow{2}{*}{$\begin{array}{l}\mathrm{N}^{\mathrm{o}} \text { de ratas } \\
\text { avaliadas }\end{array}$} & \multirow{2}{*}{$\begin{array}{c}\mathrm{N}^{\mathrm{o}} \mathrm{de} \\
\text { embriões }\end{array}$} \\
\hline & Longitudinal & Transverso & Média & & & & \\
\hline 9 & $0,37 \pm 0,07$ & $0,52 \pm 0,08$ & $0,45 \pm 0,05$ & Não feito & Não feito & 20 & 45 \\
\hline 10 & $0,44 \pm 0,07$ & $0,56 \pm 0,09$ & $0,51 \pm 0,06$ & Não feito & Não feito & 25 & 50 \\
\hline 11 & $0,51 \pm 0,10$ & $0,71 \pm 0,06$ & $0,61 \pm 0,06$ & Não feito & Não feito & 20 & 45 \\
\hline 12 & $0,55 \pm 0,05$ & $0,79 \pm 0,04$ & $0,67 \pm 0,02$ & $0,43 \pm 0,08$ & $170,0 \pm 9,7$ & 20 & 45 \\
\hline 13 & $0,58 \pm 0,08$ & $0,83 \pm 0,12$ & $0,71 \pm 0,06$ & $0,45 \pm 0,09$ & $169,8 \pm 15,8$ & 20 & 45 \\
\hline 14 & $0,69 \pm 0,08$ & $0,95 \pm 0,08$ & $0,82 \pm 0,06$ & $0,50 \pm 0,09$ & $193,6 \pm 12,5$ & 20 & 45 \\
\hline 15 & $0,78 \pm 0,14$ & $1,24 \pm 0,12$ & $0,98 \pm 0,14$ & $0,82 \pm 0,13$ & $214,7 \pm 20,3$ & 20 & 45 \\
\hline 16 & $0,87 \pm 0,06$ & $1,55 \pm 0,15$ & $1,21 \pm 0,08$ & $1,11 \pm 0,11$ & $223,6 \pm 27,6$ & 20 & 45 \\
\hline
\end{tabular}

As vesículas embrionárias foram diferenciadas de outras estruturas de formas redondas ou ovais que possuíam uma ecogenicidade similar próximo ao útero (bolos fecais, músculo psoas maior, rins). No início da pesquisa (no dia 9 ou 10), as vesículas embrionárias foram diferenciadas dos bolos fecais, a qual possuía uma estrutura redonda ou oval, com ecogenicidade podendo variar entre intermediário e alto, que não sofreu alteração em sua forma ao se exercer pressão durante a varredura na parede abdominal, o que contrasta com os resultados obtidos com a vesícula, que, por estar cheia de líquido, possui uma ecogenicidade menor e há uma alteração na forma ao se exercer pressão.

Tabela 4. Medidas ultrassonográficas aproximadas de CRR durante os dias 11 ao 16 de gestação (Ypsilantis et al., 2009)

\begin{tabular}{lc}
\hline Dias de gestação & CCR (mm) \\
\hline 11 & 2 \\
12 & 4,5 \\
14 & 8,5 \\
15 & 11,0 \\
16 & 13,5 \\
\hline
\end{tabular}

Durante a idade gestacional dos dias 10 a 14 podiam ser diferenciadas da imagem ultrassonográfica do músculo psoas maior no corte transversal. O músculo está situado ao longo da linha média do abdômen caudal, apareceu como uma estrutura oval irregular, de ecogenicidade intermediária e com bordas o circunferido hiperecóico, no qual o critério de exclusão adotado foi a ausência de estruturas embrionárias do dia 12 ao 14.

Aproximadamente no dia 15, as vesículas embrionárias poderiam ser diferenciadas dos rins, localizados na região crânio dorsal do abdômen, na área do espaço retroperitoneal, como uma estrutura oval na seção longitudinal com uma visível região cortical externa hipoecóica distinguível, região medular hiperecóica e sistema coletor hiperecóico no centro. Foi possível mensurar o pulso da artéria renal e sua frequência era igual à frequência cardíaca da rata examinada (310 a 340 bpm).

No relato descrito por Stasinopoulou et al. (2014) foi monitorado a gestação de 64 ratas Wistar, de idades de aproximadamente 18 semanas, na qual a primeira avaliação foi realizada quando estavam no dia 7 de gestação e sendo acompanhadas todos os dias seguintes pelo mesmo operador utilizando o aparelho ultrassonográfico Vivid I GE, com o transdutor linear 12L-RS na frequência de $13 \mathrm{MHz}$. Elas eram mantidas em um ambiente controlado com a temperatura a $24 \pm 2^{\circ} \mathrm{C}$, a umidade relativa em $55 \pm 10 \%$, com um ciclo de 12 horas claro/escuro, com livre acesso a água e alimentação peletizada. Para a realização do exame nas ratas, foi necessário a administração do anestésico isoflurano a $5 \%$ por via inalatória e sendo mantida por isoflurano a 2,5\%, a perda do reflexo de retirada foi a confirmação da indução anestésica, iniciando a avaliação ultrassonográfica. 
Foi no dia 8 em que primeiramente foi detectada a gestação, na qual era apenas visível o saco vitelino, uma estrutura de aparência oval para redonda cheia de líquido de anecóico a isoecóico, sem evidência de embrião. A placenta foi observada primeiramente no dia 9 como sendo uma estrutura hiperecóica presa à superfície interna do saco gestacional. Já no dia 10, era possível distinguir os fetos e o coração, esse por meio dos sinais pelo Doppler colorido, assim como a aparição dos batimentos cardíacos, porém não foi possível mensurá-lo. No dia 11, o coração estava evidentemente no modo-B, mas não foi possível estimar os batimentos cardíacos.

O fluido amniótico foi observado no dia 12, assim como foi possível avaliar as funções cardíacas através do Doppler colorido. A cauda pôde ser diferenciada, as quatro câmaras do coração e o cordão umbilical eram perceptíveis e as extremidades do feto estavam aparentes no dia 13. Do dia 14 em diante, o corpo e a cabeça tornaram-se cada vez mais distinguíveis à medida que o fato se curvava dorsalmente, o focinho levantando do tórax e a coluna vertebral era visível. O corpo foi se alongando, ficou nítida a separação entre a cabeça e o corpo e a ossificação craniana no dia 15, bem como a bexiga.

No dia 16 ocorreu o início do desenvolvimento dos tecidos ósseos, especialmente nas extremidades do corpo, com uma clara distinção das falanges; as órbitas oculares e costelas tiveram o início de seu desenvolvimento e pela primeira vez foi possível observar o aparecimento do fígado. Os ventrículos cerebrais tornaram-se vistos no dia 17, junto com a aorta cranial e caudal, estava sendo iniciado o processo de ossificação da coluna e costelas, as falanges estavam nitidamente ossificadas.

No dia 18 ficou evidente os ventrículos do coração, enquanto continuava o processo de ossificação das costelas e da coluna. $\mathrm{O}$ fígado e outros órgãos abdominais também foram discriminados. Em conclusão, no dia 19, a mandíbula era identificada dos demais ossos cranianos e os rins também podiam ser visíveis.

Dessa maneira, é possível observar que a diferença encontrada entre os autores quanto às porcentagens encontradas acerca dos diagnósticos acertados ou a evolução do crescimento dos embriões pode ser atribuída às frequências dos transdutores utilizadas nas pesquisas serem divergentes e os métodos usados serem distintos. Entretanto, a pesquisa realizada por Ypsilantis et al. (2009) e Stasinopoulou et al. (2014) conseguiram trazer diversas outras informações a respeito do crescimento embrionário, esses resultados podem servir como bases de estudos para outras pesquisas.

Ao comparar os trabalhos de Ypsilantis et al. (2009) e Stasinopoulou et al. (2014) com os dados coletados por Carmo et al. (2007), os primeiros autores conseguiram obter apenas dois dos achados (o desenvolvimento do saco vitelino e os batimentos cardíacos), enquanto o outro conseguiu alcançar uma quantidade maior de resultados diferentes (o desenvolvimento do saco vitelino, o aparecimento do coração e do cérebro, o surgimento dos membros e o início da ossificação). Todavia, apesar de algumas dessas estruturas não terem sido mostradas quando foi descrito o seu surgimento ou que tenha ocorrido em tempo diferente, isso se explica por conta de algumas dessas estruturas serem muito pequenas que necessitam de outras metodologias para serem identificadas e pela diferença de frequência adotadas pelos autores das pesquisas.

\section{Considerações finais}

Os Rattus norvegicus são amplamente utilizados em laboratórios, mas seu início como modelo de estudo só deu início no início do século 19 com a utilização do rato albino, tendo a primeira pesquisa sido documentada em 1856 na França. Eles atingem a puberdade com aproximadamente 8 semanas de vida e sua gestação pode durar entre 20 a 23 dias, o que os tornam um exemplo primoroso para experimentos a respeito do entendimento da reprodução e comportamento reprodutivo.

Por serem bastante versáteis na área de pesquisas científicas, há a necessidade por parte dos pesquisadores de assegurar quanto a um diagnóstico antecipado e preciso gestacional desses animais, com a confirmação dos números, a idade e o estágio embriológico em que se encontra. Os primeiros sinais de gravidez se apresentam apenas quando atingidos por volta do dia 13 de gestação. No entanto, autores indicam que com a utilização da ultrassonografia é possível encontrar indícios ainda mais cedo, entre o dia 8 e 9 de gestação, assim como é possível observar o desenvolvimento fetal e a possibilidade de comensurar os movimentos respiratórios fetais. 
Devido ao fato de existirem poucas pesquisas nessa área, principalmente quando se trata da ultrassonografia, a qual foram encontradas somente estudos em inglês, mostra-se necessário reforçar a importância de continuar trabalhos neste âmbito.

\section{Referências bibliográficas}

Carmo, J. C., Peter, V. M., \& Gerra, M. O. (2007). Cronologia do desenvolvimento embrionário e fetal de ratos conforme a datação do início da prenhez. Boletim do Centro de Biologia da Reprodução, 26(1/2), 5-16.

Davis, D. E. (1951). The characteristics of rat populations. American Journal of Public Health, 41(2), 158-163. https://doi.org/10.2105/ajph.41.2.158.

Galef, B. G. (2010). Norway Rats. Encyclopedia of Animal Behavior. Academic Press.

Inaba, T., Mori, J., \& Tori, R. (1986). Use of echography in rats for pregnancy diagnosis. The Japanese Journal of Veterinary Science, 48(5), 1003-1006. https://doi.org/10.1292/jvms1939.48.1003.

Krinke, G. J. (2000). The laboratory rat. Elsevier. https://doi.org/10.1016/B978-0-12-074903-4.X50006

Magalhães, L. E. (2012). A ciência e os animais de laboratório. Revista Da Sociedade Brasileira de Ciência Em Animais de Laboratório, 1(1), 7-13.

Modlinska, K., \& Pisula, W. (2020). The natural history of model organisms: The Norway rat, from an obnoxious pest to a laboratory pet. Elife, 9, e50651. https://doi.org/10.7554/eLife.50651.

Otto, G. M., Franklin, C. L., \& Clifford, C. B. (2015). Biology and diseases of rats. In Laboratory Animal Medicine (pp. 151-207). Elsevier. https://doi.org/10.1016/B978-0-12-409527-4.00004-3

Raineki, C. (2006). Manipulação neonatal, aprendizado olfatório e reprodução em ratos. Universidade Federal do Rio Grande do Sul.

Stasinopoulou, M., Mantziaras, G., Paronis, E., Balafas, E., Lelovas, P., Samara, A., \& Kostomitsopoulos, N. (2014). Use of real-time ultrasonography as an alternative method for early detection, confirmation and evaluation of rat pregnancy. Ultrasound in Medicine \& Biology, 40(6), 1372-1378. https://doi.org/10.1016/j.ultrasmedbio.2014.07.002.

Ypsilantis, P., Deftereos, S., Prassopoulos, P., \& Simopoulos, C. (2009). Ultrasonographic diagnosis of pregnancy in rats. Journal of the American Association for Laboratory Animal Science, 48(6), 734-739.

Histórico do artigo:

Recebido: 5 de outubro de 2021

Aprovado: 1 de novembro de 2021

Disponível online: 2 de março de 2022
Licenciamento: Este artigo é publicado na modalidade Acesso Aberto sob a licença Creative Commons Atribuição 4.0 (CC-BY 4.0), a qual permite uso irrestrito, distribuição, reprodução em qualquer meio, desde que o autor e a fonte sejam devidamente creditados. 